\title{
Touhuanping Fault, an active wrench fault within fold-and-thrust belt in northwestern Taiwan, documented by spatial analysis of fluvial terraces
}

\author{
Yoko Ota $^{\mathrm{a}, \mathrm{b}}$, Yu-Nung Nina Lin ${ }^{\mathrm{b}}$, Yue-Gau Chen ${ }^{\mathrm{b}, *}$, Nobuhisa Matsuta ${ }^{\mathrm{b}}$, Takuya Watanuki ${ }^{\mathrm{b}}$, Ya-Wen Chen ${ }^{\mathrm{b}}$ \\ a Yokohama National University, Japan \\ ${ }^{\mathrm{b}}$ Department of Geosciences, National Taiwan University, Taipei 106, Taiwan
}

\section{A R T I C L E I N F O}

\section{Article history:}

Received 2 October 2007

Received in revised form 18 March 2009

Accepted 28 April 2009

Available online 5 May 2009

\section{Keywords:}

Northwestern Taiwan

Touhuanping Fault

Hsincheng Fault

Drowned valley

Late Quaternary tectonics

Repeated faulting

\begin{abstract}
A B S T R A C T
This study aims at the recent activity and development of an active wrench fault, the Touhuanping Fault in northwestern Taiwan. Northwestern Taiwan has been proposed in a current situation between the mature to waning collision in terms of tectonic evolution. The main drainage in this area, the Chungkang River, flows close to the trace of the fault mentioned above. We examined various types of deformation of fluvial terraces along the Chungkang River as a key to understanding the nature and rate of the late Quaternary tectonics. The E-W trending Touhuanping Fault has long been mapped as a geological boundary fault, but its recent activity was suspected. Field survey revealed that its late Quaternary activity is recorded in the offset fluvial terraces. Our result shows dextral slip and vertical offset with upthrown side on the south, and activated at least twice since the emergence of terrace 4 (older terrace 3 with OSL date of ca. $80 \mathrm{ka}$ ). Total amount of offset recorded in the Touhuanping terrace sequence is $15 \mathrm{~m}$ for dextral and $10 \mathrm{~m}$ for vertical offset. Estimated recurrence time of earthquake rupture may be a few tens of thousand years. Uplift on the upthrown side of the Touhuanping Fault also resulted in the formation of drowned valleys which were graded to terrace 4 . Other deformation features, such as back-tilting, westward warping, and a range-facing straight scarp, were also identified. A second-order anticline roughly parallel to the Touhuanping Fault is suggested to be the origin of the northward tilting on terrace 3; it could have resulted from a flower structure on the Touhuanping Fault at shallow depth. This may demonstrate that the buried segment of the Touhuanping Fault has also been active since $80 \mathrm{ka}$. In the northern study area, the westward warping at terrace 2 probably represents late Quaternary activity of another NE-SW trending Hsincheng Fault.
\end{abstract}

(C) 2009 Elsevier B.V. All rights reserved.

\section{Introduction}

Our study area, located in northwestern Taiwan, consists of a series of fluvial terraces mainly along the northern bank of the west-flowing Chungkang River. An alluvial lowland has been extensively developed between the Chungkang River and terraced area. Densely dissected hilly land, underlain by Pliocene to Pleistocene strata lies north of the terraced area (Figs. 1 and 2). The highest hill top is $180 \mathrm{~m}$ above sea level, east of the oldest terrace at Pingding (Fig. 3) but most of the hills are lower than $100 \mathrm{~m}$ asl. In contrast, the oldest terrace T1 is 150 $160 \mathrm{~m}$ asl, stands higher than the most of surrounding hill peaks. This was resulted from the topography inversion of previously developed alluvial lowland after the emergence of the oldest terrace (Fig. 2). North of the study area, one of the industrial centers in Taiwan, the fluvial terraces are deformed by a series of reverse faults, including deformation during the Holocene (Shih et al., 1985; Chen et al., 2004).

\footnotetext{
* Corresponding author. Department of Geosciences, National Taiwan University, Taipei 10617, Taiwan R.O.C. Tel.: +8862 23697648; fax: +886223644625.

E-mail address: ygchen@ntu.edu.tw (Y.-G. Chen).
}

To the south, the Tunglo Fault system has also deformed terraces (Ota et al., 2006). Surface ruptures were reported during the 1935 earthquake ( $M=7.0$, e.g. Otuka, 1936; Lin, 2005). Shyu et al. (2005) have defined the northern area as a "waning collision domain" and southern area as "Mature collision domain", respectively, with the Chungkang River close to the boundary between these domains.

Tectonic morphology along the Chungkang River is not well described, except for Shih et al. (1985), who did general mapping of the terraces and probable active fault traces. Lin (2005) linked this area to the 1935 earthquake, especially focusing on the active dextral Touhuanping Fault. Shyu et al. (2005) also described the Touhuanping Fault, sub-parallel to the lower reach of Chungkang River, as the major boundary separating structural domains in the north and south. However, previous mapping and field observation of the fault only concluded that this is a "suspect fault" (Lin et al., 2000). Thus the nature and history of the Touhuanping Fault and its associated features have not been completely understood.

Accordingly, we focused on: (1) mapping the fluvial terraces and determining their chronology, (2) quantitatively clarifying the displacements of the Touhuanping Fault on different terraces and to 


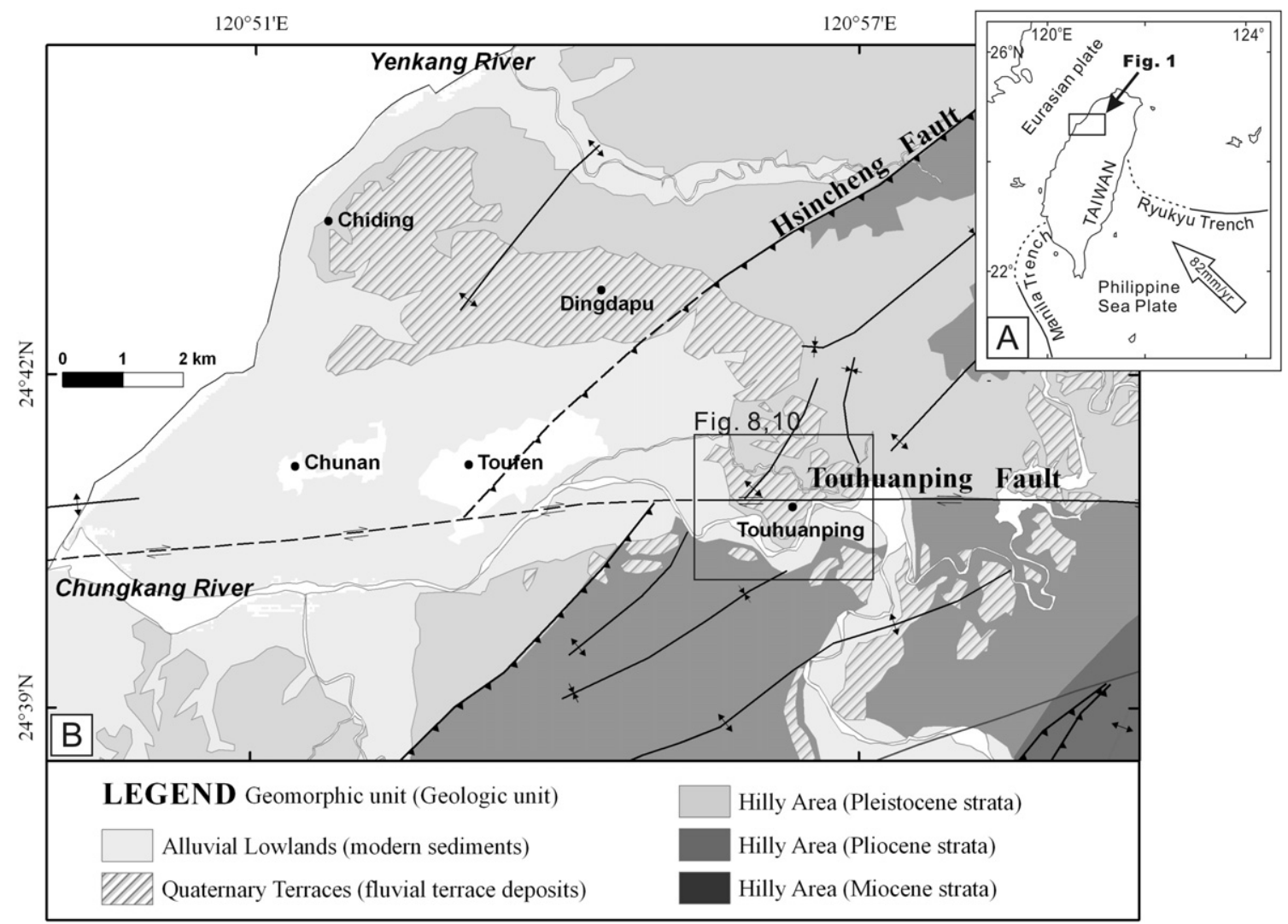

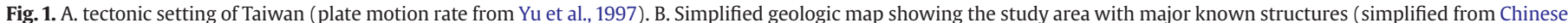
Petroleum Corporation, 1994). Touhuanping Fault strikes E-W; other major faults strike NE-SW.

work out its past activities, (3) exploring other tectonic deformation associated with the Touhuanping Fault, and (4) interpreting all the geomorphic features by a proposed structural framework.

\section{Methods}

We used aerial photographs of $1 / 20,000$ scale to map terrace distribution, tectonic deformation and landslides and to prepare a geomorphological map of the study area. For the field investigation, in addition to the observation of terrace morphology, many exposures were examined to understand the nature of terrace deposits and their deformation. Shaded relief maps based on 40-m DEM were used for the mapping and profiling. In general, we used 1:5000 topographic maps as our base map, while fault scarps and terrace risers were measured by hand-level and tape measurement in the field.

To determine the ages of terrace deposits, OSL dating method was taken to derive the last time while sediments exposed to daylight, and the underlying physical principle is presented in Aiken $(1985,1998)$. Quartz and K-feldspar are the main minerals able to apply for this method and easily found in the natural environment. The trapped charge population

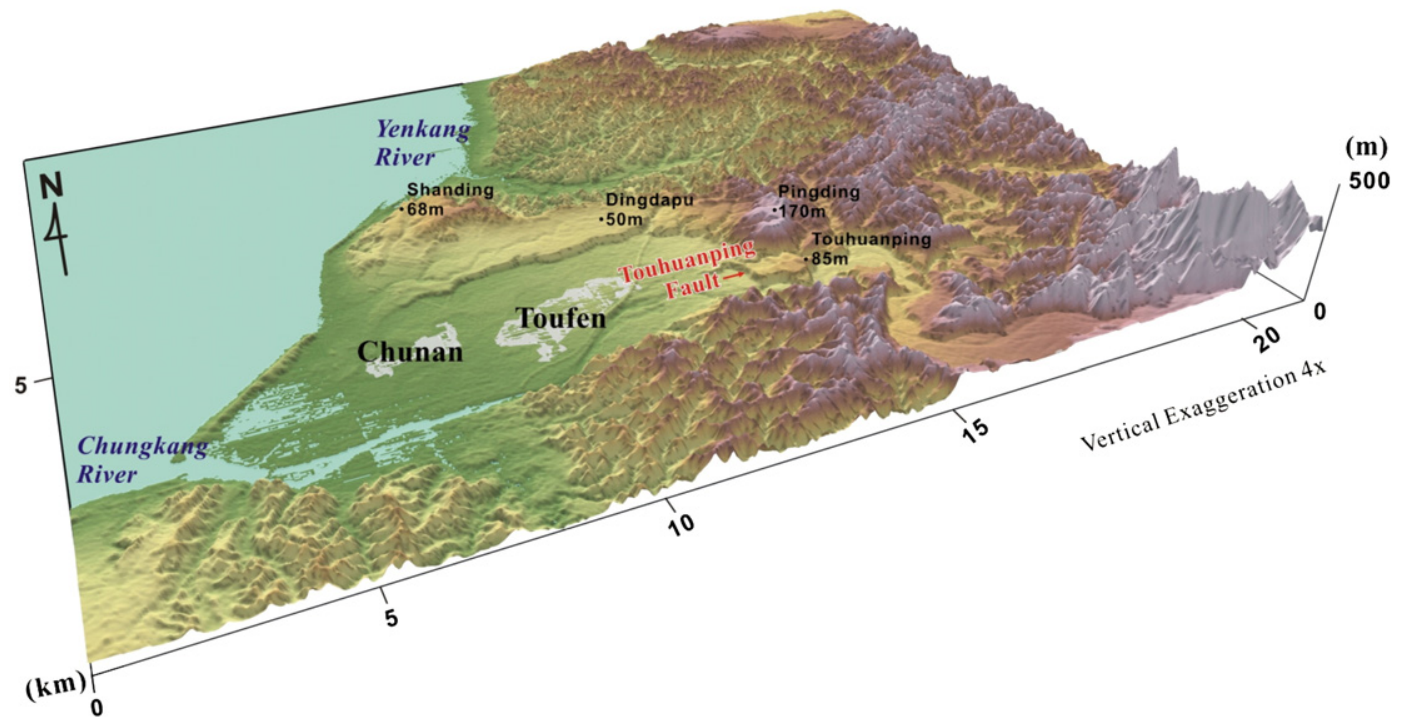

Fig. 2. Oblique view of the landform of the study area, looking northeastwards. An arrow indicates the Touhuanping fault scarp. 
Table 1

Parameters for dose rate derivation and luminescence age calculation.

\begin{tabular}{|c|c|c|c|c|c|c|c|}
\hline Sample no. & Locality & Aliquots & $\begin{array}{l}\mathrm{U} \\
(\mathrm{ppm})\end{array}$ & $\begin{array}{l}\text { Th } \\
\text { (ppm) }\end{array}$ & $\begin{array}{l}\mathrm{K} \\
(\%)\end{array}$ & \multicolumn{2}{|c|}{$\begin{array}{l}\text { Water content }{ }^{\mathrm{a}} \\
(\%)\end{array}$} \\
\hline TF05-01 & Shiping & 60 & 2.83 & 13.28 & 2.28 & \multicolumn{2}{|c|}{19.70} \\
\hline TF05-02 & Shiping & 64 & 1.10 & 4.65 & 1.10 & \multicolumn{2}{|c|}{15.50} \\
\hline TF05-05 & Touhuanping & 60 & 2.80 & 11.76 & 1.44 & \multicolumn{2}{|c|}{23.00} \\
\hline СК0618 & Dingdapu & 35 & 1.47 & 6.78 & 1.21 & \multicolumn{2}{|c|}{3.69} \\
\hline $\begin{array}{l}\text { B dose } \\
(\mathrm{Gy} / \mathrm{ka})\end{array}$ & $\begin{array}{l}\gamma \text { dose } \\
(\mathrm{Gy} / \mathrm{ka})\end{array}$ & $\begin{array}{l}\text { Cosmic ray } \\
(\mathrm{Gy} / \mathrm{ka})\end{array}$ & \multicolumn{2}{|c|}{$\begin{array}{l}\text { Dose rate }{ }^{b} \\
(\mathrm{~Gy} / \mathrm{ka})\end{array}$} & \multicolumn{2}{|l|}{$\begin{array}{l}D_{\mathrm{e}} \\
(\mathrm{Gy} / \mathrm{ka})\end{array}$} & $\begin{array}{l}\text { Age } \\
\text { (ka) }\end{array}$ \\
\hline$\overline{1.70}$ & 1.20 & 0.15 & 3.05 & & $248.3=$ & & $81.3 \pm 3.6$ \\
\hline 0.79 & 0.50 & 0.15 & 1.44 & & $116.7 \pm$ & & $81.2 \pm 3.1$ \\
\hline 1.21 & 0.97 & 0.15 & 2.33 & & $59.7 \pm$ & & $26.5 \pm 2.3$ \\
\hline 1.07 & 0.73 & 0.15 & 1.95 & & $149.8 \pm$ & & $76.9 \pm 2.7$ \\
\hline
\end{tabular}

a The water content after sample taken was measured and assumed as the same through the entire buried period.

b The radioactivities of samples are derived from individual concentrations of elements based on Aiken (1985).

due to the effects of ionizing radiation was accumulated in grains of quartz and K-feldspar after burial. The OSL signals in response to the trapped charges increase by time due to the continuous irradiation from the surrounding deposits. The single aliquot regenerative-dose (SAR) protocol (Murray and Wintle, 2000) is applied to deduce the equivalent dose $\left(D_{\mathrm{e}}\right)$ which is the radiation dose received during the burial. The energy absorbed from the natural ionizing radiation per thousand years is measured as a dose rate. Therefore, the OSL age is given as:

$\operatorname{Age}(\mathrm{ka})=D_{\mathrm{e}}(\mathrm{Gy}) /$ Dose rate $(\mathrm{Gy} / \mathrm{ka})$

At outcrop samples were taken by punching PVC plastic tubes into the target sedimentary layers, and all the routine processes are done in the dark room back to the OSL laboratory. The silt-sized grains $(90-150 \mu \mathrm{m})$ are sieved out and cleaned with $\mathrm{HCl}$ and $\mathrm{H}_{2} \mathrm{O}_{2}$ as the usual way. In order to obtain the clean quartz grains, $\mathrm{HF}$ is used to remove the other unnecessary minerals and the alpha particle affected outer layer of the grains. All the measurements have been done with Risø TL/OSL-DA-15 set up in the Department of Geosciences, National Taiwan University. Samples were stimulated with blue LEDs (470 nm) and detected through Hoya U-340 filter. Dose rates are measured by ICP-MS (for U and Th) and XRF (for K) and listed in Table 1.

\section{Fluvial terrace along the Chungkang River}

\subsection{Terrace classification and distribution}

Fluvial terraces along the Chungkang River are classified into six major steps from the highest (T1) to the lowest (T6), as shown in Fig. 3. We also provided longitudinal profile of projected terraces relative to the present riverbed along the Chungkang River to constrain the terrace correlation (Fig. 4). Terrace distribution and heights are outlined below.

The highest and oldest terrace (T1) exists in only two locations. One is a wide terrace at Pingding north of Touhuanping, about 150-160 m asl. Terrace deposits at Pingding are highly weathered fluvial gravels with capping reddish soil, and some bedrock hills are sticking out from the terrace surface. The other is located further west and is also a wide terrace near Shanding. Its height is $\sim 70 \mathrm{~m}$ asl in the north and $50 \mathrm{~m}$ asl in the south, showing considerable southward sloping (Figs. 2 and 3). No T1 terrace exists between these two localities. However, very small intermediate terrace remnants (T1b) are locally preserved at ca.120 m asl on the west of T1 at Pingding.

The second highest terrace (T2) is found near the same two locations. One is the northwest of Pingding and $100 \mathrm{~m}$ asl in maximum, and the other is south of $\mathrm{T} 1$ at Shanding and is up to $45 \mathrm{~m}$ asl T2 is also capped by reddish soil on the top.

Terrace T3 is widely developed, and is especially continuous westward from Shiping, where it is at an altitude of ca. $70 \mathrm{~m}$ asl and almost reaches its maximum width to ca. $1.5 \mathrm{~km}$ at Dingdapu.

Terrace T4 is mostly observed in the Touhuanping area, and the lowest T5 and T6 are only recognized near Touhuanping.

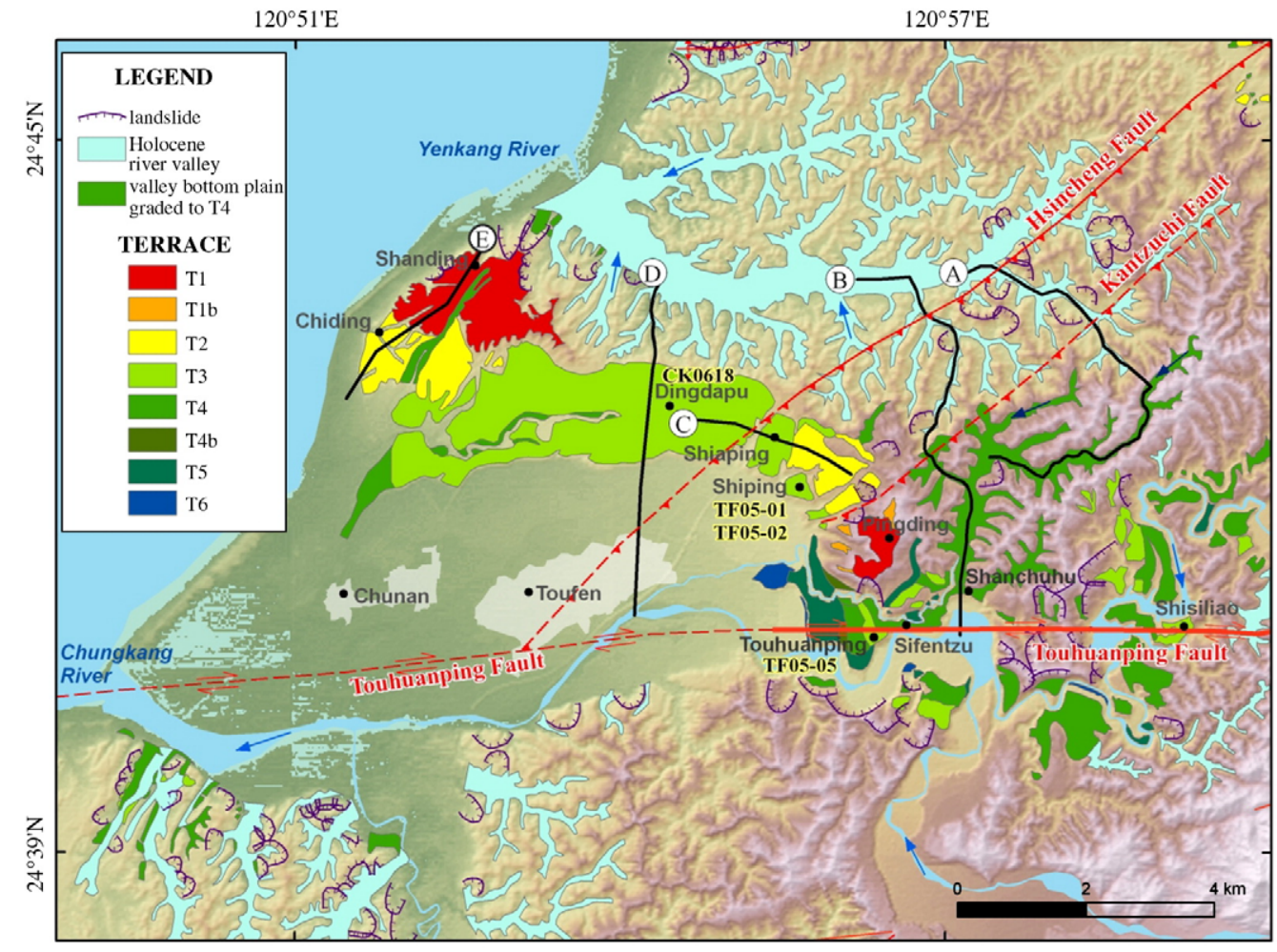

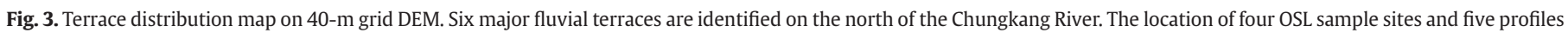
are also shown. Lines A and B locate profiles shown in Fig. 7. 


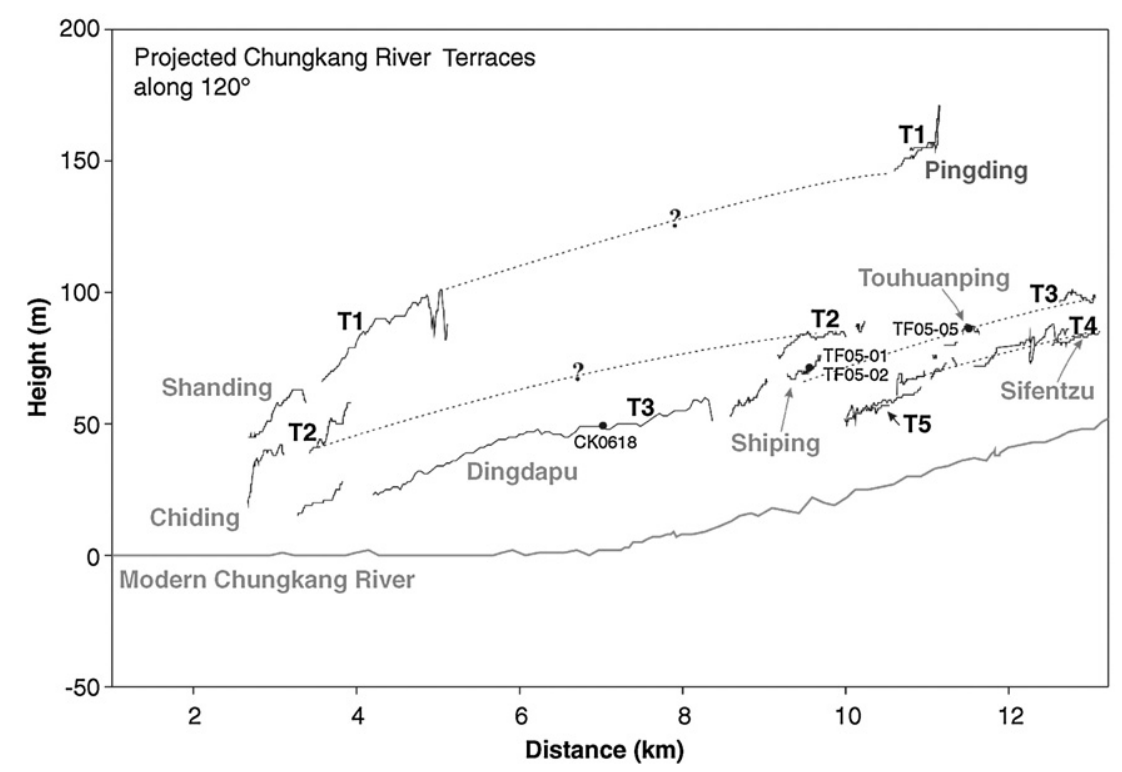

Fig. 4. River-parallel plot of fluvial terraces on the northern bank of the Chungkang River. Terrace T3 is most continuously developed. OSL sample sites are also shown.

Fig. 4 is a river-parallel profile along an azimuth of $120^{\circ}$ with projected fluvial terraces. T3 is continuous and is treated as a single terrace. T1 and $\mathrm{T} 2$ present only the east and west of the study area. However, their correlation seems to be reasonable, judging from relative of terrace heights.

\subsection{Terrace deposits and their age}

We examined the terrace deposits, especially their degree of weathering and presence of reddish soil. T1 to T3 terraces usually have reddish soil, weathered from over-bank deposits on top of gravel beds.
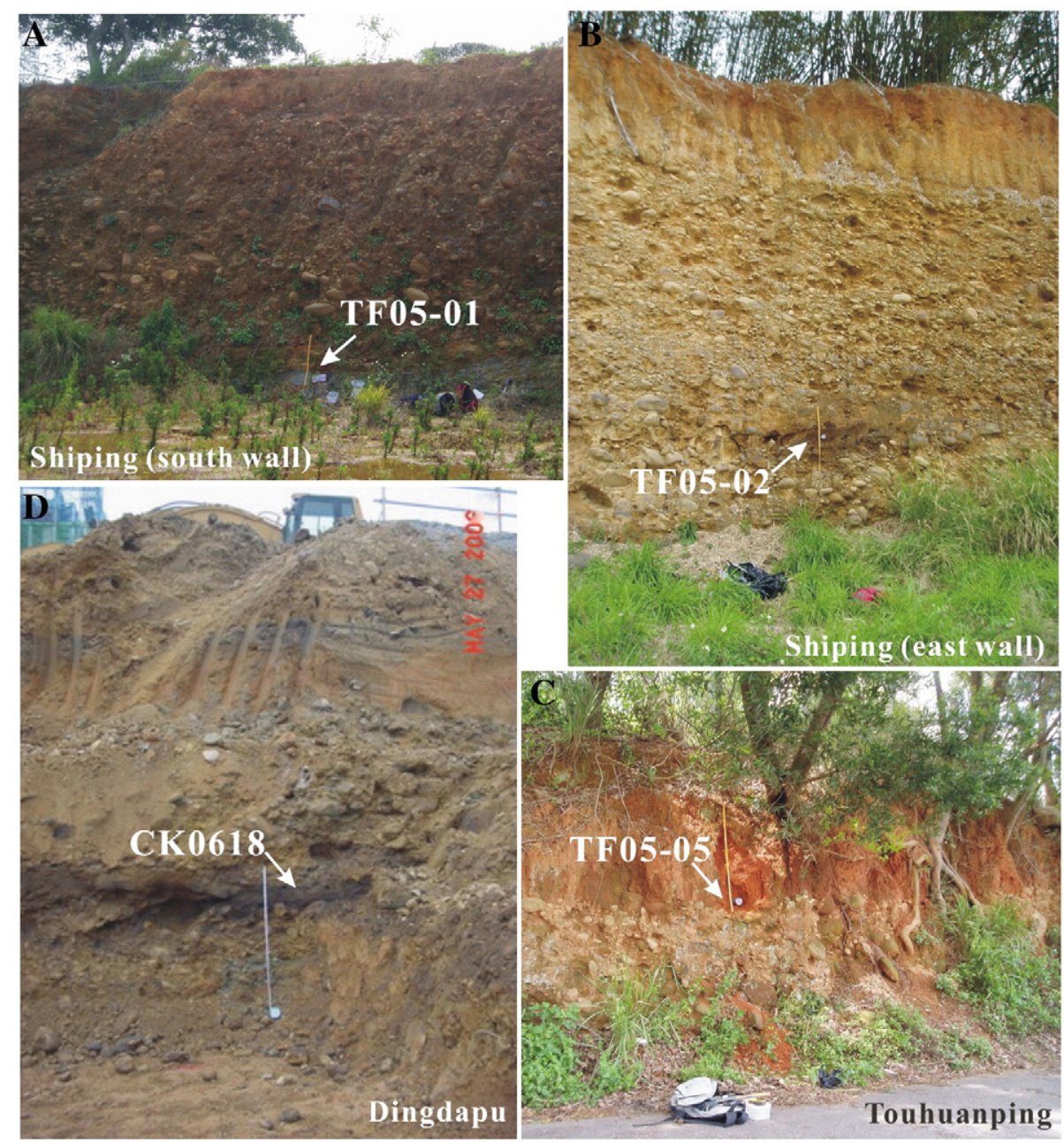

Fig. 5. Profiles of OSL samples from T3 terrace. A. TF05-01, B. TF-05-02, C. TF05-05, D. CK0618. Locations are shown in Fig. 3. 
We assume the minimum age for the reddish soil is ca. 30,000 yr BP, because on the southern part of the 1999 earthquake fault, the terrace with a radiocarbon age of $\mathrm{ca}$. 30,000 yr BP has no reddish soil, while terraces above it have distinct reddish soil (Ota et al., 2002). Therefore we suppose that $\mathrm{T} 3$, the youngest lateritic terrace is older than 30,000 yr BP. To confirm the age estimate, we sampled deposits at three sites for OSL dating (Fig. 3, Table 1).

Sample TF05-01 and TF05-02 were both taken in the T3 terrace near Shiping (Fig. 3). A large quarry exposed the terrace deposit in a $7-8 \mathrm{~m}$ high outcrop (Fig. 5A-B). Within the profile, the lower $6 \mathrm{~m}$ is a thick gravel layer with embedded blackish-brown lenticular silt layers embedded, and the top 2-3 $\mathrm{m}$ is laterized sand. In the lowest $50 \mathrm{~cm}$, Pliocene bedrock was exposed. TF05-01 was taken from the lenticular sandy layer right above the bedrock on the south wall, and TF05-02 was taken from a similar sandy layer but $1 \mathrm{~m}$ higher than TF05-01 on the east wall. The equivalent dose (ED) results of small aliquots show that TF05-02 has narrow normal distribution, while the TF05-01 is wider (Fig. 6A-B). We used the method of mean ED average to compute the ages. They are $81.3 \pm 3.6 \mathrm{ka}$ and $81.2 \pm 3.1 \mathrm{ka}$ for TF05-01 and TF05-02 respectively.

Sample TF05-05 was taken from a road cut within the T3 terrace at Touhuanping (Fig. 3). The profile was $3 \mathrm{~m}$ high, showing lower $1.5 \mathrm{~m}$ as gravel layer overlain by upper $1.5 \mathrm{~m}$ laterized coarse sand (Fig. 5C). The condition of this outcrop is not ideal for OSL sample because laterization is relatively strong and bioturbation was also considerable. However, this is the only outcrop available around the Touhuanping area, thus we took a sample as possible as close to the boundary between gravel and sand. In addition to a distinct peak between 20 and $100 \mathrm{~Gy}$, the ED distribution presents 10\% scattered unbleached aliquots (Fig. 6C). The mean age is $26.5 \pm 1.3 \mathrm{ka}$.

Sample CK0618 was taken near Dingdapu, on the widest T3 terrace in the lower reach of Chungkang River. It was taken in a construction site in the industrial park, and the total profile depth is about $7 \mathrm{~m}$ (Fig. 5D). From top to bottom is $2-3 \mathrm{~m}$ of artificial fill, $1.5 \mathrm{~m}$ of paleosol and 2.5-3.5 $\mathrm{m}$ of fluvial cobbles. No bedrock is exposed. The outcrop is freshly excavated, and we observed very minor bioturbation in the sampling position. We took sample from a blackish-brown layer within the cobbles, and the ED distribution is a clear normal distribution (Fig. 6D). Age from this sample is $76.9 \pm 2.7 \mathrm{ka}$. Detailed information of each sample is presented in Table 1.

The ages of T3 terrace deposits are inconsistent; two of the three samples in the lower reach yield age 77-83 ka, while the other collected at Touhuanping yields a totally different age of 25-27 ka. Since the outcrop condition of TF05-05 may be unacceptable, we so far take the 77-83 ka as the age of T3 surface along the middle to lower reach of Chungkang River. However, we cannot deny the possibility that the flight of terraces in the Touhuanping area is actually younger, which may imply a higher uplift rate in the middle reach. To solve this problem, more reliable ages are needed in the future.

\subsection{Morphology of valley bottom plain}

Many small streams densely dissect the hilly area north of the Chungkang River terraces. These streams are currently almost dry under common conditions and have very wide valley bottoms, despite their small drainage areas. The surface of the valley bottom plains is flat with a gentle gradient slope except for the valley head (Fig. 7). Pattern and morphology of these valley bottom plains suggest that they originated from drowned valleys. The Holocene transgression is one of possible periods to form these features. It is believed that they underwent tectonic influence, since the valley widths and heights are significantly different between northward and southward flowing streams towards the Yenkang River and the Chungkang River respectively (Figs. 3, 7). For northward flowing streams, valley bottom plain is $300 \mathrm{~m}$ in maximum width and height is lower than ca. $40 \mathrm{~m}$ asl. For southward flowing streams, width reaches to 400-500 m, and valley bottom plain is ca. $100 \mathrm{~m}$ asl. (Fig. 7). It is very interesting that these southward flowing valleys merge to $\mathrm{T} 4$, whereas northward
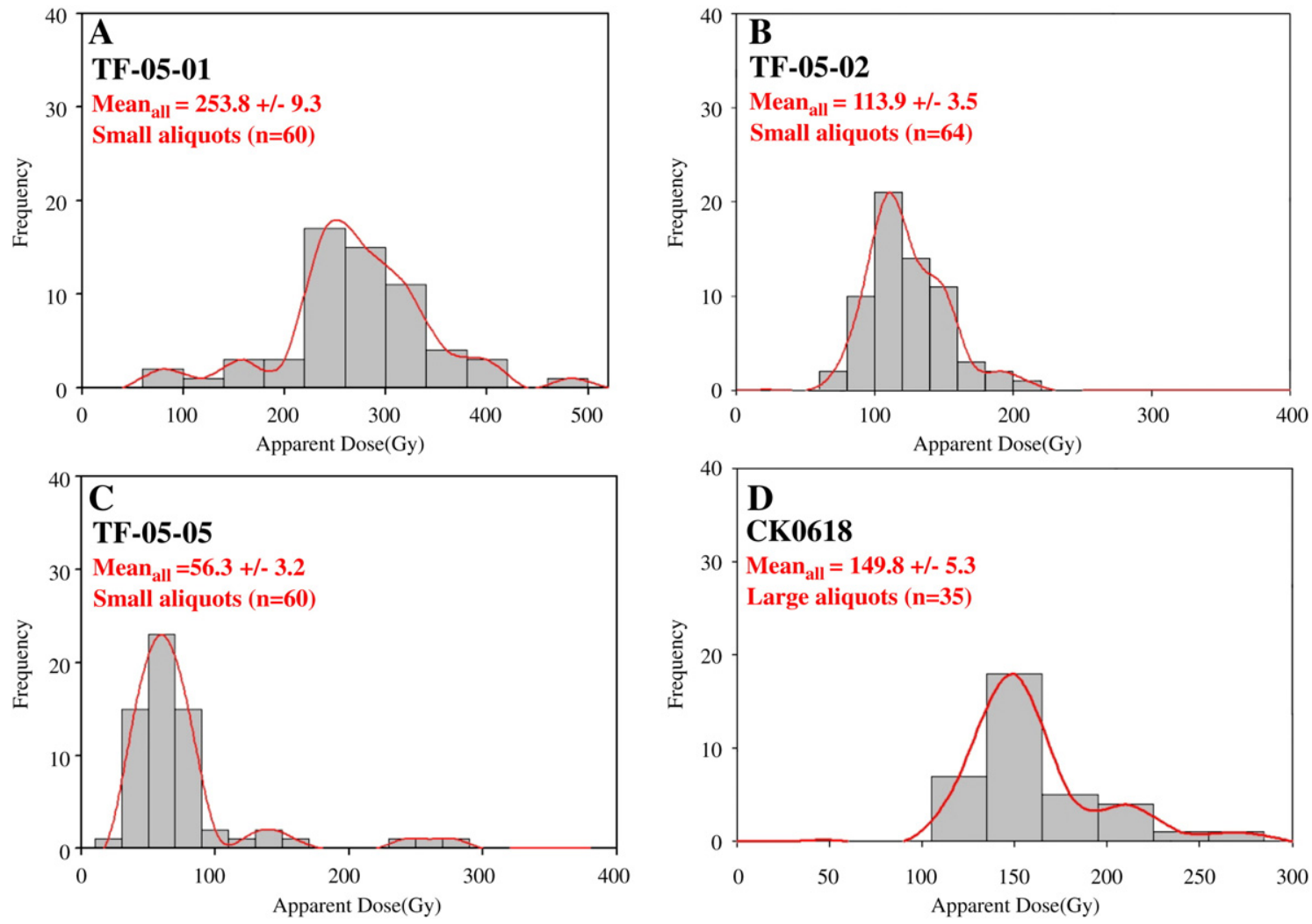

Fig. 6. Signal distribution of four OSL samples. 

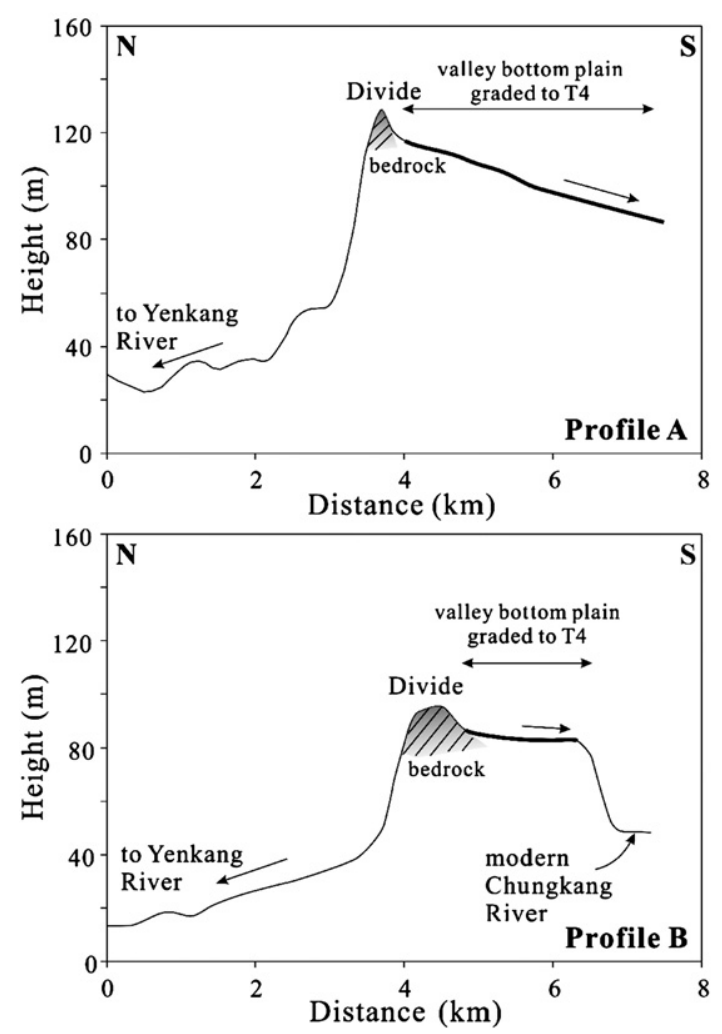

Fig. 7. Profile A and B: comparison of valley bottom plain profiles between the north and southward direction drawn by 40 -m grid DEM. Note a remarkable height difference of the valley bottom between the south (shown in thick line) and north side of the divide. While the valley bottom plain of the north of the divide grades to the Yenkang River flood plain, that of the south side grades to T4 terrace. See Fig. 3 for the location of profiles and text for the discussion. flowing valleys merge to the modern flood plain. Profiles A and B of Fig. 7 clearly show the height difference (about $50 \mathrm{~m}$ ) between the two oppositely-flowing valley bottom plains, although they are very closely located, and the drainage divide is not very clear in map view (Fig. 3). Such a characteristic difference has not been pointed out before. We discuss tectonic significance on this phenomenon in a later section.

\section{Touhuanping Fault}

The Touhuanping Fault has long been a geologically known fault, which juxtaposes late Pliocene Cholan Formation and Pleistocene Toukoshan Formation to the south and north respectively (Fig. 1). Although Shih et al. (1985) mapped this fault as active based on geomorphic observations, to date, the Touhuanping Fault is still considered as only a suspect active fault since no strong evidence of Quaternary activities has been found (Lin et al., 2000; Shyu et al., 2005). In this study, we describe the nature and amount of offset, and the related tectonic implications.

\subsection{Identification of the Touhuanping Fault}

The terraces T3, T4 and T5 mentioned above have been cut by a straight fault scarp, striking E-W and facing north (Fig. 8). Confirmed length of the fault scarp cutting the terraces is only $1.5 \mathrm{~km}$, but the fault scarp stands as a very distinct feature (Fig. 9) through the small but densely populated town of Touhuanping. However, we were unable to trace this scarp either westwards or eastwards, because the area to the west of the terraces is a low-lying alluvial plain and to the east is hilly. Neither setting is favorable for the detection and preservation of recent faulting evidence. In fact, we tried to trace this scarp eastward, because the geologically known fault extends $7 \mathrm{~km}$ eastwards. After carefully checking of aerial photos and then conducting the field survey, we found two possible places for the surface expression of the fault at Sifentzu and Shisiliao (Fig. 3). At

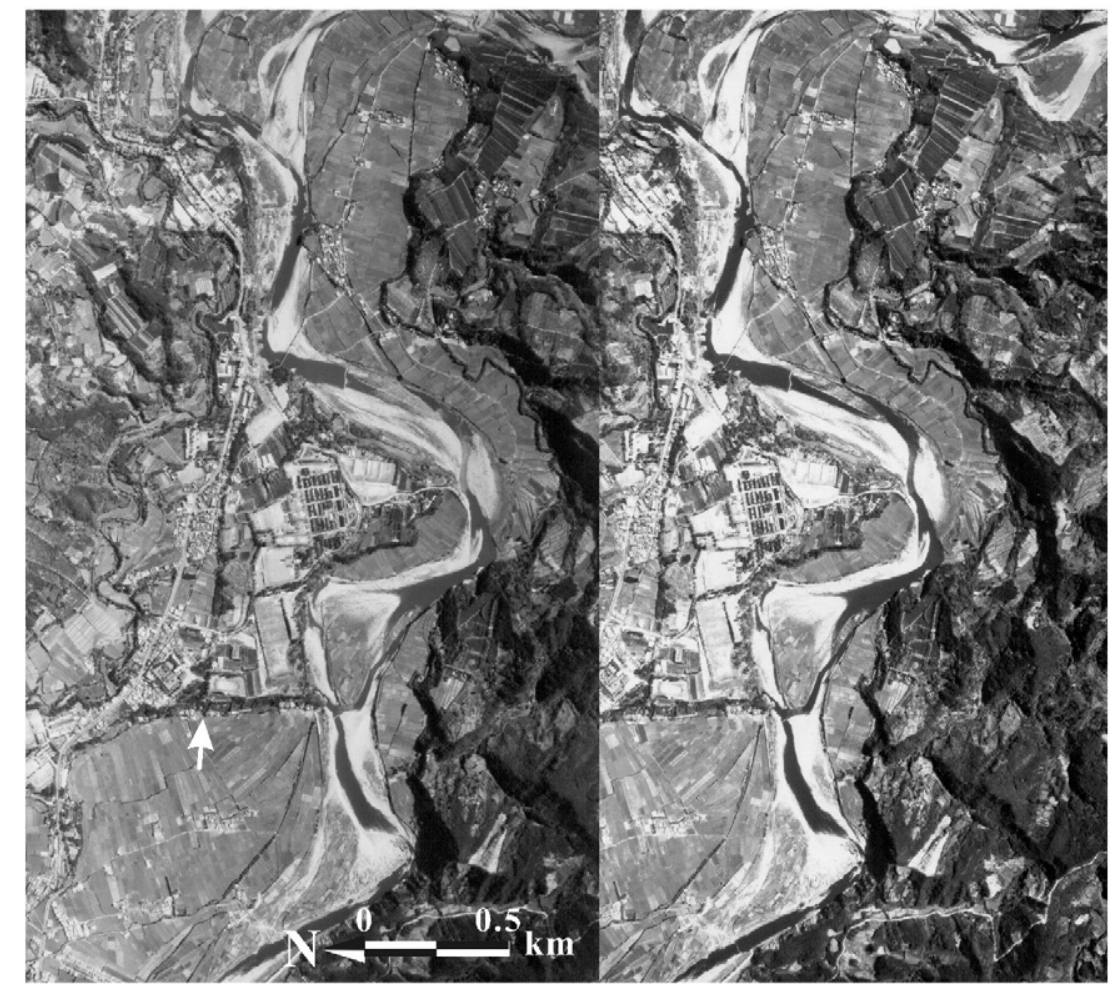

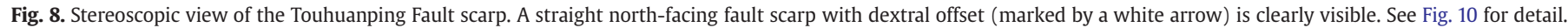




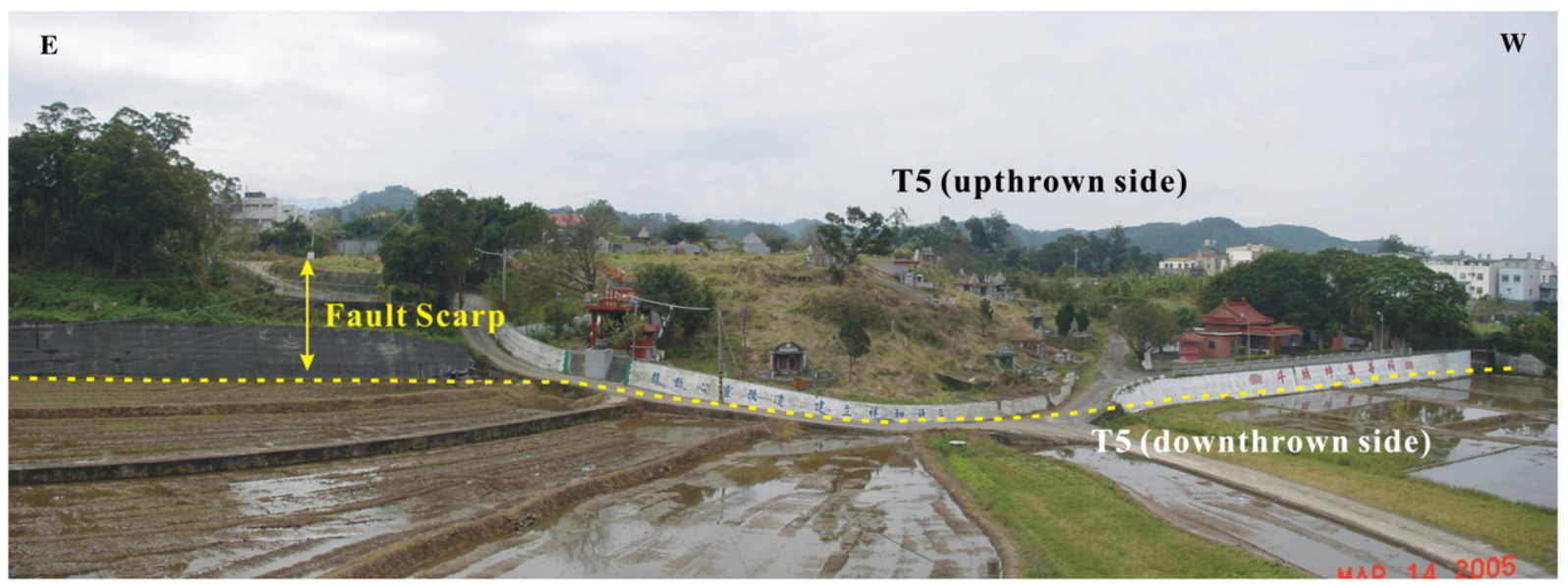

Fig. 9. Photo of the western part of the Touhuanping fault scarp on T5 (looking southward).

Sifentzu, the southern side of County Road 124 is higher than the north. However, because of the lateral erosion of the Chungkang River, the supposed upthrown side preserved only $10 \mathrm{~m}$ in width. At Shisiliao, south of the possible fault trace, T3 terrace is higher than the same terrace to the north, probably suggesting the presence of a tectonic scarp. If these two sites can be confirmed as the evidence of surface deformation, the fault length extends to about $6 \mathrm{~km}$. In this case, the length of the active fault is roughly the same as geologically identified fault. However, west of Touhuanping, both the geologic and active fault trace are buried by modern deposits.

Another important line of evidence for the active fault is the dextral offset along the Touhuanping Fault, although this is preserved only on the terraces at Touhuanping (next section).

\subsection{Offset and repeated activity}

Fig. 10 illustrates the distribution of terraces and fault at Touhuanping. The fault trace is straight, as already mentioned. This indicates that the fault plane should be high or even angle vertical, although no fault exposure is observed. The Touhuanping Fault cuts all terraces, but no deformation is observed on the narrow Holocene terrace (T6) along the western margin of the Touhuanping terrace series, implying that no faulting took place during the Holocene. The terraces T3, T4, and T5 are easily distinguished and are separated by terrace risers at a high-angle intersection with the fault trace. The T4 group can be subdivided into T4 itself and T4b on the upthrown side. In addition to the vertical offset, right-lateral slip is clearly shown by the offset of terrace risers.

We measured the scarp height to establish two profiles for each terrace. The vertical offset from $\mathrm{T} 3$ and $\mathrm{T} 4$ are nearly the same, ranging from $9.3 \mathrm{~m}$ to $10.6 \mathrm{~m}$ (Table in Fig. 11), whereas the vertical offset of T5 is only 4.3 to $5.9 \mathrm{~m}$ about a half of the amount of above T3 and T4. Based on the assumption that vertical offset in one event was ca. $5 \mathrm{~m}$, it can be derived that the earthquake rupturing took place twice in the past. The penultimate event was after the emergence of T4, and the latest one was after the emergence of T5 (Fig. 12). Vertical offset by each faulting is ca. $5 \mathrm{~m}$. Long-term vertical slip rate is estimated $\sim 0.14 \mathrm{~m} / \mathrm{ka}$.

In addition to the vertical offset, the Touhuanping Fault also produces dextral offset, as shown in the offsets of terrace risers (Fig. 10). Dextral offset of the terrace riser between T3 and T4 is quite

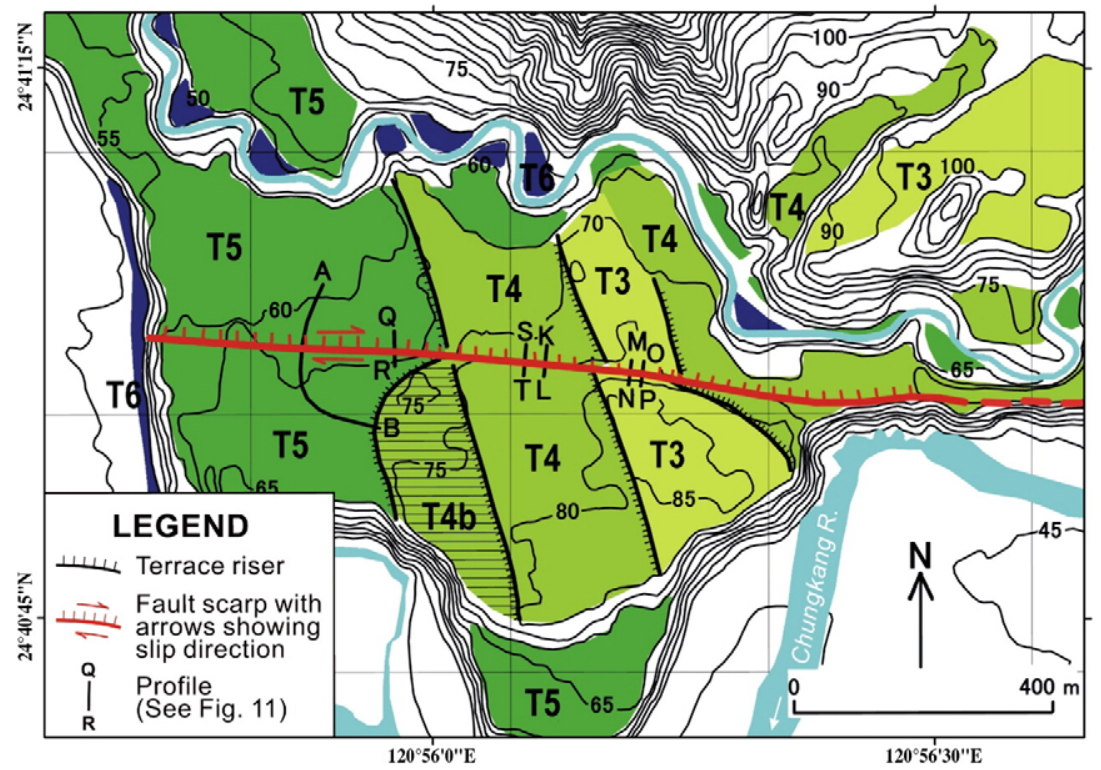

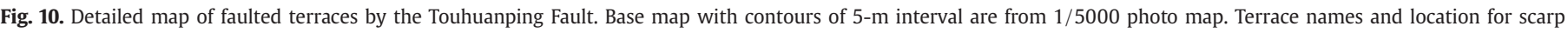

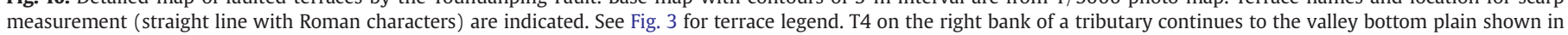
profile A and B of Fig. 7. 


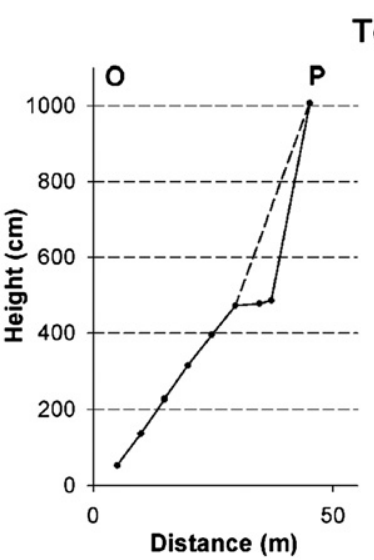

\section{Terrace T3}

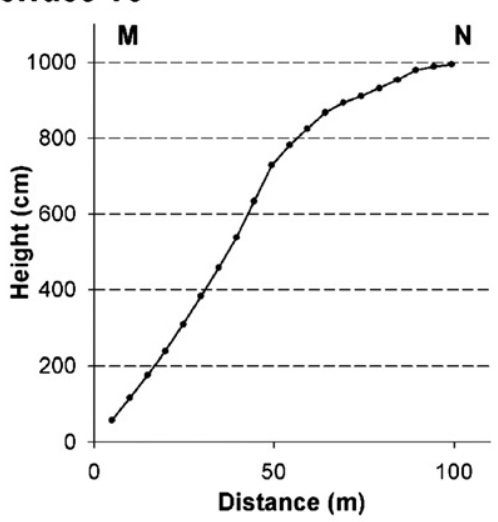

Terrace T4

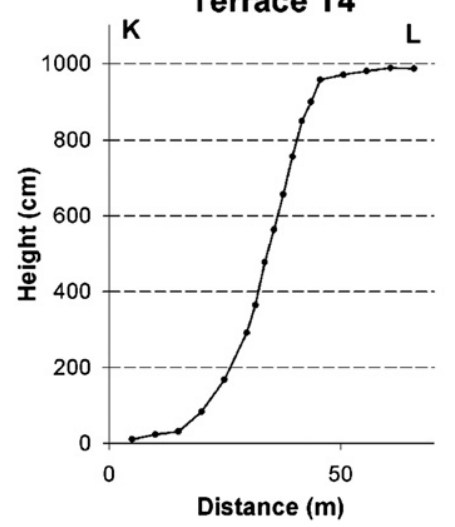

Fault scarp height

\begin{tabular}{|l|l|r|}
\hline \multirow{2}{*}{ Terrace 3 } & OP & $10.6 \mathrm{~m}$ \\
\cline { 2 - 3 } & MN & $9.8 \mathrm{~m}$ \\
\hline \multirow{2}{*}{ Terrace 4 } & $\mathrm{KL}$ & $9.3 \mathrm{~m}$ \\
\cline { 2 - 3 } & $\mathrm{ST}$ & $10.1 \mathrm{~m}$ \\
\hline \multirow{2}{*}{ Terrace 5 } & QR & $5.9 \mathrm{~m}$ \\
\cline { 2 - 3 } & AB & $>4.3 \mathrm{~m}$ \\
\hline
\end{tabular}

Fig. 11. Examples of the profiles across the Touhuanping Fault scarp measured in the field. A break in profile OP is caused by an artificial modification, and then dashed line can be the original profile. All the measured scarp height is summarized in a table right bottom of this figure. See Fig. 10 for the location of profiles. Note the same amount of vertical offset for T3 and T4.

clear, reaching ca. $15 \mathrm{~m}$. A riser bounding the western margin of T4 on the downthrown side seems to be continuous with that of $\mathrm{T} 4$ on the upthrown side without any offset. However, this riser is supposed to link back to that of T4b if dextral slip did happen before. Curved outline of the riser may be due to erosion by previous meandering stream. As for the T5 terraces, the recent erosion by main stream resulted may have taken away the riser offset caused by the last event. Assuming two faulting events occurred after the emergence of T4, the 15 -m dextral offset is a sum of two events, thus the amount of dextral offset by a single event may come to ca. $7 \mathrm{~m}$, which is larger than the amount of vertical offset $(5 \mathrm{~m})$. Therefore the Touhuanping Fault is characterized as dextral slip dominant fault with a long recurrence interval and relatively slow slip rate (net slip of $\sim 0.17 \mathrm{~m} / \mathrm{ka}$ ). Fig. 12 illustrates the relation between the terrace formation and faulting events according to the discussion above.

\subsection{Significance of Touhuanping Fault for recent geomorphic development}

Even though the slip rate is rather small, the uplift of the southern side of the Touhuanping Fault still significantly contributes to the evolution of drainage system. Two streams (A and B in Fig. 3) flow down from the valley bottom plains in the northeast of Touhuanping terraces confluent at Shanchuhu. They do not enter directly into the Chungkang River, but flow westward on the downthrown side of Touhuanping Fault (Fig. 10). We interpret that such a deflected drainage pattern is controlled by the uplift of the southern side (upthrown side) of the Touhuanping Fault, which probably resulted in the formation of a temporary lake as a local base level by fault scarp created dam. The valley bottom plains with uncommon width and high altitude (see Section 3.3 above; Figs. 3 and 7 ) are only limited to the streams east of the Touhuanping terraces, which can be explained by uplift of the southern side of Touhuanping Fault. When the first event occurred after the emergence of T4, the southward flowing branches in the footwall were dammed, causing sediment accumulation and wide valley bottoms graded into T4. As a summary, the Touhuanping Fault as an active fault controls the drainage system and results in the contrasting feature of valley bottom plains on the downthrown side.

\section{Other deformation of terraces}

\subsection{West facing flexural scarp at Shiping}

In the Hsinchu area to the north, active reverse faults have been reported. Among them the Hsincheng Fault, striking NE-SW, is a major structure (Fig. 3). Its tectonic deformation and repeated activities have been well-documented (Chen et al., 2004). Beside of the Hsincheng Fault, Shih et al. (1985) proposed another active fault, the Kantzuchi Fault, extending southwestwards across the hilly area and deforming the terraces in the north of the Chungkang River (Fig. 3). Both of these faults run through the hilly area, which is composed of unconsolidated Toukoshan Formation, the Pleistocene molasse (Fig. 1). Due to the unconsolidated nature of the parent materials in this hilly area, it is therefore difficult to preserve the relevant geomorphic features. Except for a few linear valleys sub-
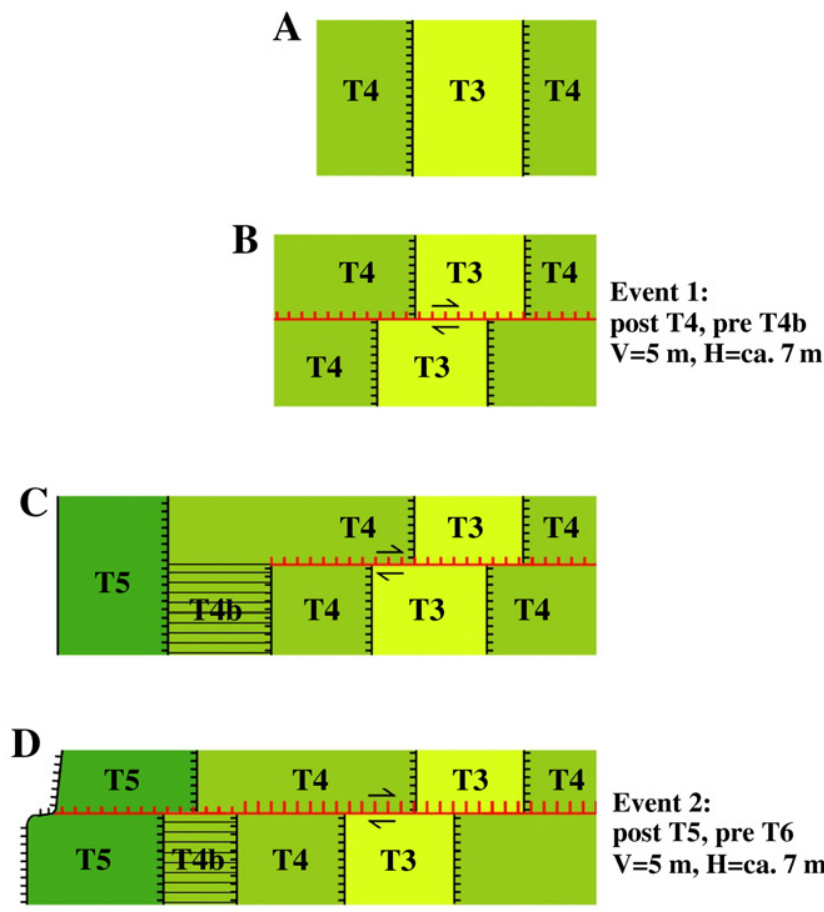

Event 2: post $\mathrm{T} 5$, pre $\mathrm{T} 6$ $\mathrm{V}=\mathbf{5} \mathrm{m}, \mathrm{H}=$ ca. $7 \mathrm{~m}$

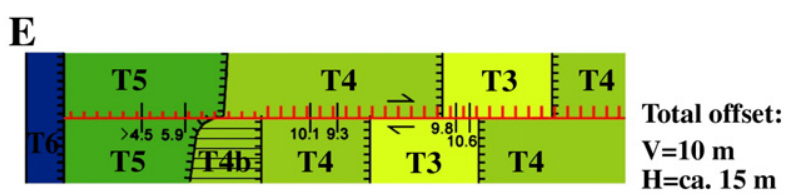

Fig. 12. Schematic diagram to interpret the relationship of terrace formation and two faulting events of the Touhuanping Fault. See text for terrace evolution history (A-E). 
parallel to the strike of the faults, no other solid evidence for recent faulting was found. However, at Shiping we found a NNE striking scarp between $\mathrm{T} 2$ and $\mathrm{T} 3$, and dipping abnormally west, showing a convex profile with ca. $12 \mathrm{~m}$ scarp height (Fig. 3, and profile C in Fig. 13). This scarp shape cannot be attributed to either stream erosion or the original fluvial terrace surface. We therefore propose this is a flexural scarp probably caused by rupturing of a reverse fault. However, without further subsurface information we cannot identify which fault is responsible for this feature. Judging from the extension of the Hsincheng Fault, the linear valley west of Shiping may correspond to the Hsincheng Fault as mapped by Shih et al. (1985). However, except for the linear valley no other positive evidence of the activity has been observed. Also if we extend the strike of the Kantzuchi Fault smoothly, the flexural scarp of T2 seems to be located farther west than the extension line. Thus, at this stage we cannot determine which fault was active after the formation of the T2 terrace. However, we tend to correlate this scarp to the Hsincheng Fault, because this well-known fault is rather close, but eastward from the mapped trace. If it is the southern extension of the Hsincheng Fault, the active fault length will be ca. $20 \mathrm{~km}$, which is long enough to cause a large earthquake. Also it means the Hsincheng Fault has been active during the past $80 \mathrm{ka}$.

\subsection{Back tilting of T3 terrace in lower reach of Chungkang River}

Near Dingdapu a very wide T3 terrace extends for $6 \mathrm{~km}$ long subparallel to the Chungkang River with maximum width of $2 \mathrm{~km}$ (Figs. 3 and 4). Its height is $65 \mathrm{~m}$ and $30 \mathrm{~m}$ asl. on the east and west, respectively, showing a westward gradient, similar to that of modern Chungkang River (Fig. 4). A noticeable feature of this terrace is the northward tilting from the southern edge (profile D in Fig. 13), resulting in an east-west trending depression in the middle of the terrace. A small river and one step of a narrow younger terrace (T4 west of profile line D in Fig. 3) are therefore developed along this depression. They are anomalous as an expression of the transverse profile of the fluvial terrace, and hence we regard them as of tectonic origin.

Initially, we considered the possibility of the existence of an active syncline to interpret this E-W trending depression. However, after careful observation along the northern edge of the terrace, we found that bedrock is exposed near the inner margin of the terrace (profile $\mathrm{D}$ in Fig. 13), and in some cases, alluvial fan deposits derived from hills cover the inner edge. Thus there is no positive evidence of tectonic tilt on the northern part. We propose that the tilting only occurs in the
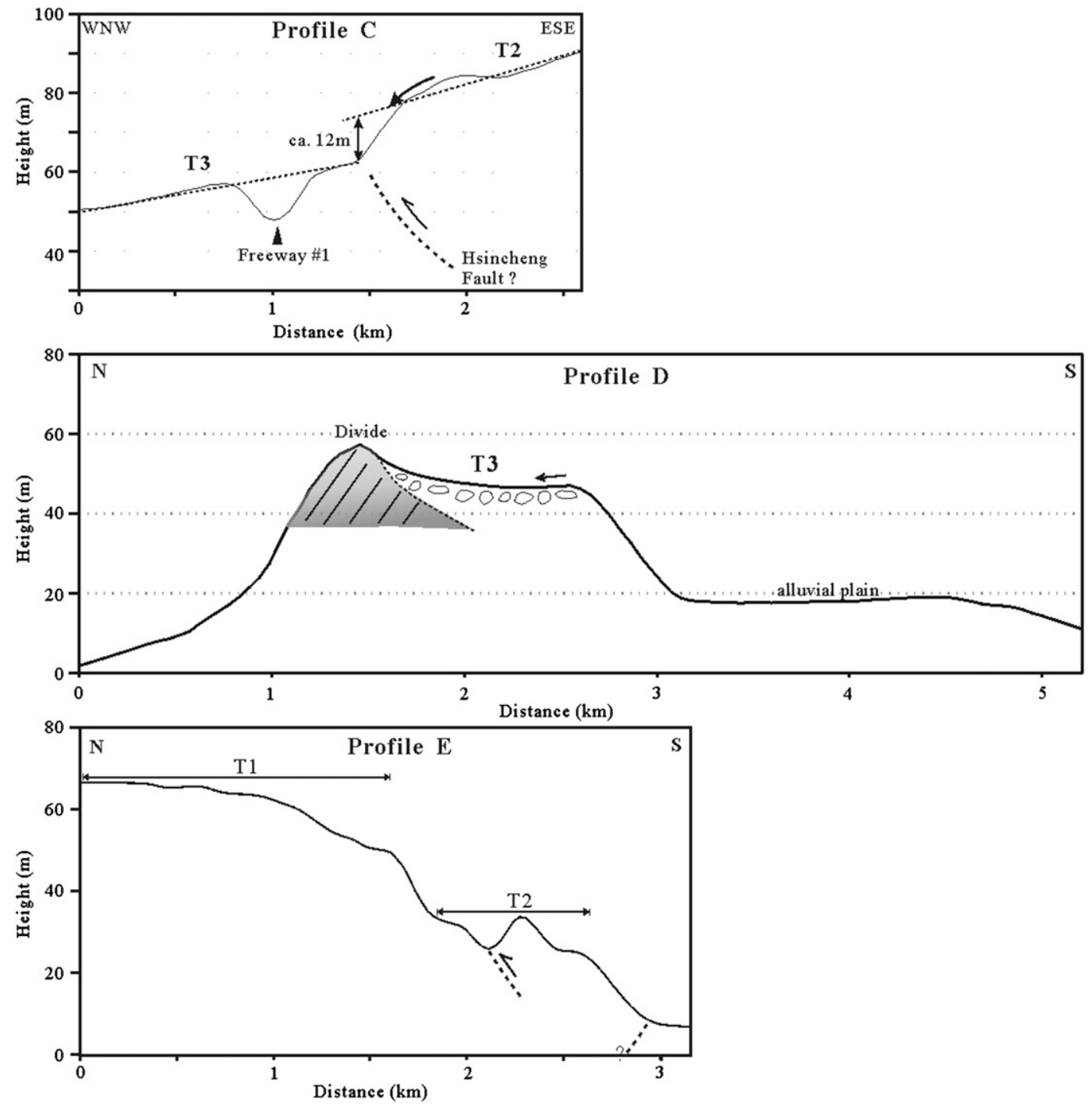

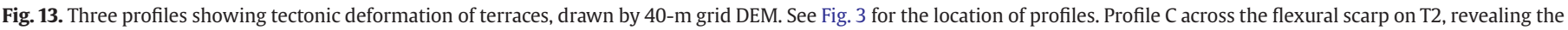

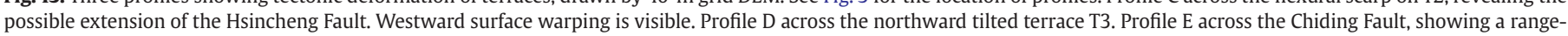
facing scarp on T2 and southward tilting of T1 and T2 terraces. 
southern part of the terrace and it may be caused by an unmapped structure developed in the south where the Chunan-Toufen basin is located. Based on the deformation characteristics, this unmapped structure may be a reverse fault or anticline parallel to the Touhuanping Fault.

\subsection{SE trending scarp near Chiding}

A scarp facing NE truncates T2 terrace at Chiding on the westernmost part of the study area, (Fig. 3, profile E in Fig. 13). This scarp emerges immediately at just east of Chiding railway station (west of terrace rise of T2) and strikes southeastward for nearly $1 \mathrm{~km}$. The scarp height near the station is about $10 \mathrm{~m}$ and decreases southeastward. This scarp cannot be attributed to the erosion of the main stream because it is almost perpendicular to major streams. Therefore, we suggest that this is a tectonic scarp. Since it is a range-facing scarp (Profile E in Fig. 13), it may be caused by a reverse fault branched from the main fault. So far, the exact location of the main fault, however, is unclear due to urbanization and absence of information on subsurface geology in Chunan-Toufen basin. In addition, we did not find extension of this scarp on the T3 and T4 terraces, so the activity of this fault is probably small.

\section{Discussions}

\subsection{Estimation of recurrence interval of the Touhuanping Fault}

The Touhuanping Fault is undoubtedly an active fault, expressed as a clear north-facing scarp with dextral offset. Displacement per event may be a maximum of as ca. $5 \mathrm{~m}$ and $7 \mathrm{~m}$ for vertical and strike slip respectively. At least two earthquake associated rupture events can be identified by reconstructing terrace evolution history (Fig. 12). The first confirmed event occurred after the emergence of T4, and prior to the formation of T4b. Unfortunately no age control is available for T4 and T4b. According to the OSL ages of 77-83 ka from T3 in Shiping and Dingdapu, T4 should be younger than these. The second observed event occurred after the formation of T5 and prior to T6, which seems to have formed in the Holocene. Hence, at least two faulting events

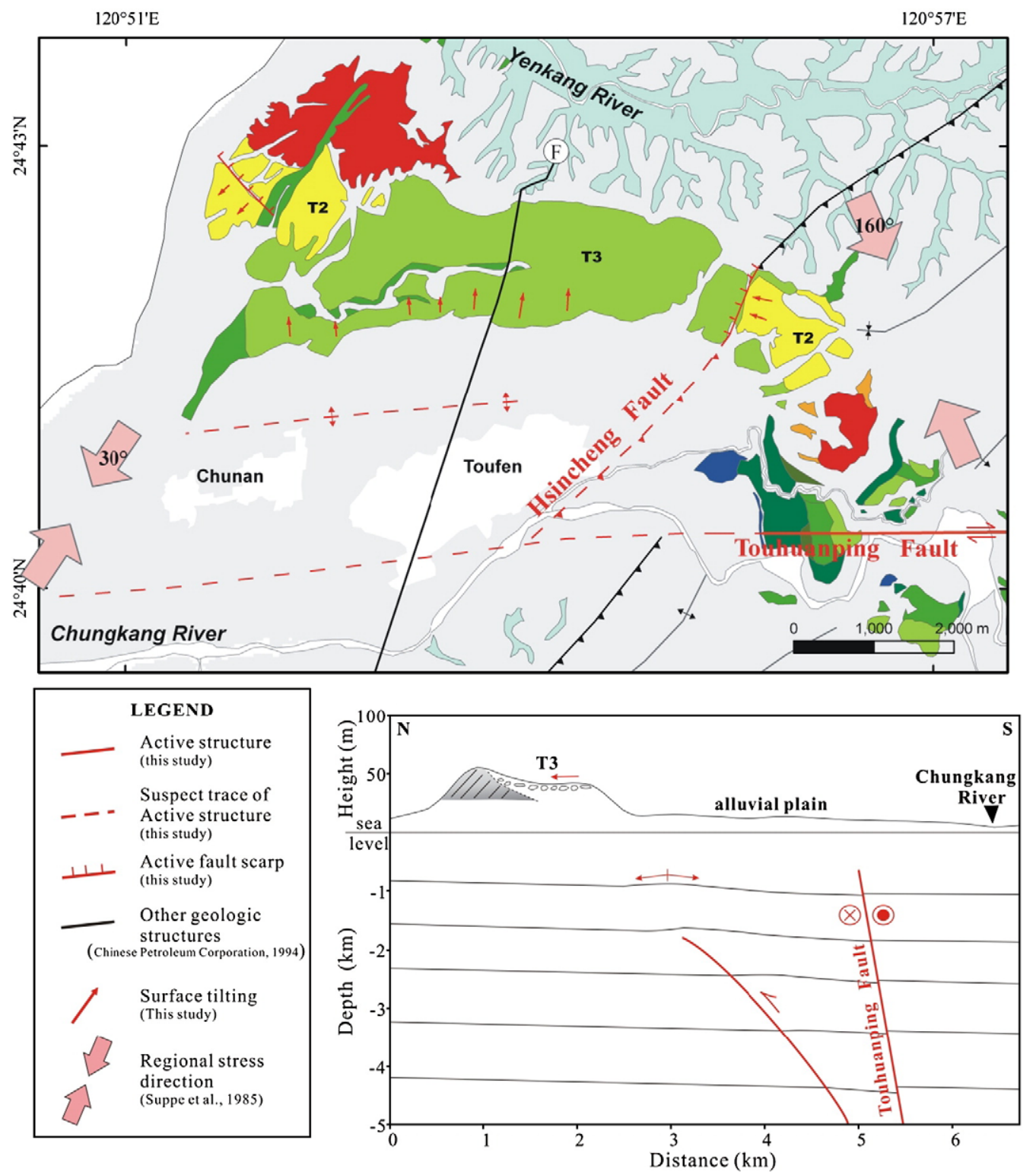

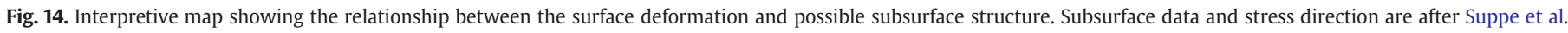

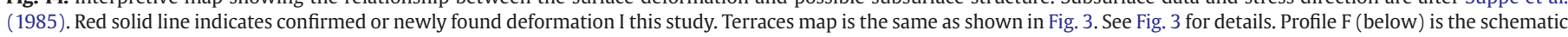
cross-section showing the possible flower structure of the Touhuanping Fault and the accompanied gentle anticline. 
happened in the past less than $80 \mathrm{ka}$, suggesting the recurrence interval is long enough. It may be a few tens of thousand years, while the exact interval could not be determined. This seems to be too long for an active fault with a clear scarp as Touhuanping Fault.

We recall another active fault which also has a rather long recurrence interval. It is the White Creek Fault in the northern part of South Island, New Zealand. A geologically known fault, truncating bedrock but with no offset is recorded on a flight of fluvial terraces of the Buller River that were formed at ca. 20,000 years ago. It was not regarded as an active fault until the Murchison earthquake $(M=7.8)$ occurred in 1929. Surface rupture with a clear fault scarp and offset terrace risers along the fault trace were reported related to this earthquake (Berryman, 1980). Up to $3 \mathrm{~m}$ of left lateral and vertical offset was observed. This indicates that a long seismic recurrence interval may be true, and after a quiescence of 20,000 years, a preexisting fault could still be reactivated and generate earthquake with surface rupture. This example may reflect the case of the Touhuanping Fault, especially a large earthquake in 1935 occurred in the adjacent area to the south.

As we mentioned above, the confirmed fault trace is only $1.5 \mathrm{~km}$ long. It certainly is too short to generate a single event with vertical slip of $5 \mathrm{~m}$ and strike slip of $7 \mathrm{~m}$. However, to the west of the confirmed segment of the Touhuanping Fault is a low-lying alluvial plain, underlain by thick alluvial deposits (Fig. 3). The westward extension of the fault trace may be buried since this youngest geomorphic surface was developed after the last event. Actually, the lowest terrace, T6, also recorded no displacement, therefore the latest event probably occurred before the formation of T6. In the immediate north of the alluvial lowland, the northward tilt of T3 presents, indicating the action of underground flower structure along this westward segment. If we only consider the possible burial fault trace on land, it may extend $10-15 \mathrm{~km}$ from our terrace sites westward. To the east of the presence of Touhuanping Fault trace on the terraced region, we failed to find geomorphic evidence except for two sites mentioned before, east of Touhuanping, because of rapid erosion on unconsolidated sediments. However, the geologically confirmed fault length can be extended at least $20 \mathrm{~km}$ eastward. As a summary, the entire fault length should be around $30 \mathrm{~km}$ from eastern hills to the western coastal zone. If we further consider the possible submarine extension, the fault length must be even larger than the value above.

\subsection{Tectonic and geomorphic significance of the Touhuanping Fault and} other structures

Geologically the Touhuanping Fault is a main tear fault, which disrupts the NE-SW striking reverse fault, the Hsincheng Fault (Fig. 1; Yang et al., 1997). Along the 20-km long geologically defined fault line, the segment east of the Touhuanping area has strong evidence of Quaternary activity as discussed above. However, west of Touhuanping, we have no evidence other than the northward tilting of the T3 terrace at Dingdapu (Fig. 3, profile D in Fig. 13). According to Yang et al. (1997), the Touhuanping Fault is characterized by a flower structure, and it is possible that the northward tilting at Dingdapu was caused by a gentle anticline that originated on one of the branch faults from the flower structure (Fig. 14). There are two reasons to support this deduction: (1) The tilting axis is sub-parallel to the strike of the Touhuanping Fault. (2) The study of borehole breakouts yielded a regional horizontal compressional direction of $\mathrm{N} 20^{\circ} \mathrm{W}$ but locally a $\mathrm{N} 30^{\circ} \mathrm{E}$ datum located at Chunan (Suppe et al., 1985; Fig. 14); this local stress anomaly is consistent with the development of an E-W striking anticline. In such a case, the Touhuanping Fault and its flower branches in the lower reach of the Chungkang River can be regarded as active during the past $80 \mathrm{ka}$.

Besides of the active Touhuanping Fault, the Hsincheng Fault may also be active in this region during the late Quaternary, since the T2 surface has been warped (Fig. 3, profile C in Fig. 13). The horizontal compressional stress derived from borehole breakouts, $\mathrm{N} 20^{\circ} \mathrm{W}\left(160^{\circ}\right)$, also favors activity on the Hsincheng Fault (Fig. 14). As for the Chiding straight scarp near the coast, we tentatively interpret it as a secondorder structure, since its strike seems obscure and its linkage with other structures remains unknown.

\section{Conclusions}

In northwestern Taiwan, we confirm that the major wrench fault, the Touhuanping Fault, is an active fault and reactivated at least twice with an approximate recurrence interval of a few tens of thousand years based on the progressive deformation discovered on different river terraces. Total amount of the vertical offset is $10 \mathrm{~m}$ and that for dextral offset is ca. $15 \mathrm{~m}$. Displacement per event is ca. $5 \mathrm{~m}$ and $7 \mathrm{~m}$ for vertical and strike slip respectively, if only two events. The uplift of the downthrown side (southern side) of the fault resulted in the landform development such as the formation of deflected drainage pattern and dammed stream valley. We also found a west-facing flexural scarp, which is probably a southwestern extension of the NE-SW striking Hsincheng Fault, another major active fault in northwestern Taiwan that has had repeated activity in late Quaternary. In addition, E-W trending northward tilting on the T3 terrace in the lower reach of Chungkang River was identified. We interpreted it as an anticlinal tilting related to the flower structure of the Touhuanping Fault, which may demonstrate activity of the Touhuanping Fault west of Touhuanping where fluvial sediments concealed all lines of evidence. We also assumed the presence of unnamed structure on the western margin of the study area, judging from the presence of a range-facing scarp.

\section{Acknowledgements}

Funding for Ota on this study was partly supported by the Japanese Geological Survey and National Science Council of Taiwan. This study was also funded by grants to Chen numbered of NSC94-2119-M-002002 and NSC95-2119-M-002-041. The funding from the Central Geological Survey of Taiwan was also critical to our field work. We further thank Shiuh-Tsann Huang and Kenn-Ming Yang in Exploration and Development Research Institute of the Chinese Petroleum Corporation, Taiwan for valuable discussion on the structure and geometry of the Touhuanping Fault.

\section{References}

Aiken, MJ. 1985. Thermoluminescence Dating. Academic Press, London.

Aiken, M.J., 1998. An Introduction to Optical Dating: The Dating of Quaternary Sediments by the Use of Rhoton-stimulated Luminescence. Oxford University Press, Oxford.

Berryman, K.R., 1980. Late Quaternary movement on White Creek Fault, South Island, New Zealand. New Zealand Journal of Geology and Geophysics 23, 93-101.

Chen, Y.G., Shyu, J.B.H., Ota, Y., Chen, W.S., Hu, J.C., Tsai, B.W., Wang, Y., 2004. Active structures as deduced from geomorphic features: a case in Hsinchu area, northwestern Taiwan. Quaternary International 115/116, 189-199.

Chinese Petroleum Corporation, 1994. Geological Map of Miaoli $(1: 100,000)$. Chinese Petroleum Corporation, Taipei.

Lin, C.W., Chang, H.C., Lu, S.T., Shih, T.S., Huang, W.J., 2000. An introduction to the active faults of Taiwan (second edition): explanatory text of the active fault map of Taiwan, scale 1:500,000 (in Chinese) Central Geological Survey Special Publication $13122 \mathrm{pp}$

Lin, Y.N., 2005. Surface deformation and seismogenic structure model of the 1935 Hsinchu-Taichung Earthquake (MGR=7.1), in Miaoli, northwestern Taiwan. Master Thesis, National Taiwan University.

Murray, A.S., Wintle, A.G., 2000. Luminescene dating of quartz using an improved single-aliquot regenerative-dose protocol. Radiation Measurements 32, 57-73.

Ota, Y., Lin, Y.N., Chen, Y.G., Chang, L.H., Hung, J.H., 2006. Newly found Tunglo active fault system in the fold and thrust belt in northwestern Taiwan, deduced from deformed terraces. Tectonophysics 417, 305-323.

Ota, Y., Shyu, J.B.H., Chen, Y.G., Hsieh, M.L., 2002. Deformation and age of fluvial terraces south of the Choushui River, central Taiwan and their tectonic implications. Western Pacific Earth Sciences 2, 251-260.

Otuka, Y., 1936. The earthquake of central Taiwan (Formosa), April 21, 1935, and earthquake faults (in Japanese) Bulletin of the Earthquake Research Institute. University of Tokyo. Supplementary volume 3, 22-74. 
Shih, T.T., Teng, K.H., Chang, J.C., Yang, G.S., 1985. The active faults and geomorphic surfaces of Chutung Tableland in Taiwan. Geographical Studies 9,1-16 (in Chinese). Shyu, J.B.H., Sieh, K., Chen, Y.G., Liu, C.S., 2005. The neotectonic architecture of Taiwan and its implications for future large earthquakes. Journal of Geophysical Research 110, B08402.

Suppe, J., Hu, C.H., Chen, Y.J., 1985. Present-day stress directions in western Taiwan inferred from borehole elongation. Petroleum Geology of Taiwan 21, 1-12.
Yang, K.M., Ting, H.H., Wu, J.C., Chi, W.R., 1997. Geological model for complex structures and its implications for hydrocarbon exploration in northwestern Taiwan. Petroleum Geology of Taiwan 31, 1-42.

Yu, S.B., Chen, H.Y., Kuo, L.C., 1997. Velocity field of GPS stations in the Taiwan area. Tectonophysics 274 (1-3), 41-59. 